\title{
"EU NÃO CONSIGO RESPIRAR": RACISMO ESTRUTURAL E OS DESAFIOS DA EDUCAÇÃO PARA AS RELAÇÕES ÉTNICO-RACIAIS NA REDE FEDERAL DE EDUCAÇÃO PROFISSIONAL, CIENTÍFICA E TECNOLÓGICA - BRASIL
}

\author{
Xênia de Castro Barbosa ${ }^{1}$ \\ Roselaine Luzitana Fracalossi Kokkonen ${ }^{2}$ \\ Sândi Barros de Sousa ${ }^{3}$
}

\section{RESUMO}

Este artigo visa contribuir para o debate público acerca do racismo estrutural no Brasil e os desafios que ele representa para a Rede Federal de Educação Profissional, Científica e Tecnológica. O estudo foi conduzido em abordagem qualitativa com base no método da pesquisa bibliográfico-documental. O corpus documental do estudo foi constituído pela Lei 10.639, de 9 de janeiro de 2003, pela Resolução n. 1, de 17 de junho de 2004, que instituiu as Diretrizes Curriculares Nacionais para a Educação das Relações Étnico-Raciais e para o Ensino de História e Cultura Afro-Brasileira e Africana, pela Lei 11.645/08, de 10 de março de 2008 e dissertações e teses que tangenciam o assunto. A coleta de dados foi realizada na internet, tanto no buscador Google quanto no Catálogo de Dissertações e Teses da CAPES, a partir do descritor "relações étnico-raciais", filtro temático "área de Educação" e filtro temporal "anos de 2017, 2018 e 2019". Os resultados indicam que o racismo é estrutural à sociedade brasileira e constitui um de seus principais desafios. Provêm de nossa experiência colonial, que articulou colonialismo e colonialidade, autoritarismo e violência, mas é também produzido e reproduzido no presente. Por se tratar de um problema multidimensional o combate ao racismo requer profundas transformações econômicas, sociais, políticas e culturais.

Palavras-chave: Educação; Desigualdades; Preconceito racial.

\section{"I CAN'T BREATHE": STRUCTURAL RACISM AND THE CHALLENGES OF EDUCATION FOR ETHNIC-RACIAL RELATIONS IN THE FEDERAL NETWORK FOR PROFESSIONAL, SCIENTIFIC AND TECHNOLOGICAL EDUCATION - BRAZIL}

\footnotetext{
${ }^{1}$ Doutora em Geografia pela Universidade Federal do Paraná. Docente do Instituto Federal de Educação, Ciência e Tecnologia de Rondônia e do Programa de Mestrado em Rede Nacional em Educação Profissional e Tecnológica (ProfEPT). E-mail: xenia.castro@ifro.edu.br

${ }^{2}$ Especialista em Coordenação Pedagógica pela Universidade Federal de Rondônia. Acadêmica do Mestrado em Rede Nacional em Educação Profissional e Tecnológica (ProfEPT). E-mail: rose_kokkonen@hotmail.com

${ }^{3}$ Especialista em Metodologia do Ensino Superior pelo Centro Universitário São Lucas. . Acadêmica do Mestrado em Rede Nacional em Educação Profissional e Tecnológica (ProfEPT). E-mail: $\underline{\text { sandibarros.nutri@hotmail.com }}$
} 
This article aims to contribute to the public debate about structural racism in Brazil and the challenges it poses for the Federal Network of Professional, Scientific and Technological Education. The study was conducted in a qualitative approach based on the method of bibliographic-documentary research. The documentary corpus of the study was constituted by Law 10.639, of January 9, 2003, by Resolution no. 1, of June 17, 2004, which instituted the National Curricular Guidelines for the Education of Ethnic-Racial Relations and for the Teaching of Afro-Brazilian and African History and Culture, by Law 11.645 / 08, of March 10, 2008 and dissertations and theses that touch the subject. Data collection was carried out on the internet, both in the Google search engine and in the CAPES Dissertations and Theses Catalog, using the descriptor "ethnic-racial relations", thematic filter "Education area" and temporal filter "years 2017, 2018 and 2019". The results indicate that racism is structural to Brazilian society and constitutes one of its main challenges. They come from our colonial experience, which articulated colonialism and coloniality, authoritarianism and violence, but it is also produced and reproduced in the present. As it is a multidimensional problem, combating racism requires profound economic, social, political and cultural changes.

Keywords: Education; Inequalities; Racial prejudice.

\section{INTRODUÇÃO}

No Brasil, a transição do escravismo para o trabalho assalariado e da monarquia para a república se deu de forma dependente ao capitalismo e periférico a ele, mantendo formas de racionalidade e de relações sociais herdadas de seu passado colonial que reproduzem uma estrutura racializada de dominação de classe. Diante disso, é fundamental uma análise em perspectiva histórica que tome como ponto de partida a relação entre escravidão e racismo e cartografe seus desdobramentos no tempo e no espaço (RIBEIRO, 2019).

Por muito tempo se acreditou que as desigualdades entre negros e brancos e as violências impostas aos primeiros em razão da cor da pele ou de sua etnia/raça eram meros resquícios de nosso passado colonial e que tenderiam a desaparecer na medida em que relações industriais de perfil capitalista se impusessem sobre todo o território nacional (BASTIDE, FERNANDES, 2008). O que vemos hoje, contudo, é a permanência do racismo e novos gradientes de violência, em que interseccionalidades de cor/raça, classe social, gênero e religião se acumulam sobre um mesmo problema. Subjaz aos discursos e práticas violentas que atingem a população negra e, sobretudo, a população negra e pobre, uma ideologia racial que se materializa não só em ações individuais como na própria estrutura do Estado. 
A existência de uma ideologia racista consolidou-se no início de nossa vida republicana por meio da política de Embranquecimento, que apoiada pelo Estado atuou no suporte à emigração de europeus para o Brasil com o intuito de desenvolver a economia cafeeira e clarear a população nacional, conferindo-lhe "as virtudes da raça caucasiana" e sublimando os "desvios e vícios" dos negros. Desmascaradas as falácias das teorias pseudocientíficas sobre a superioridade branca, persistem agora outras, que negam a existência do racismo (e que negam, portanto, um sem fim de situações de violência e exclusão social que a população afrodescendente sente na pele todos os dias,) ou que afirmam haver tão somente preconceito - expresso em perspectiva individual, negando sua existência coletiva, institucional e estrutural. Assim, contra todos os fatos há ainda os que apregoam o mito da democracia racial brasileira e negam que a violência e o genocídio imposto à população negra e pobre tenham conexão com o racismo.

Ao passo em que avançam o autoritarismo, os discursos negacionistas, conspiratórios e anticientíficos a História é cada vez mais convocada a apresentar argumentos que coloquem limites à má fé. Reafirma-se assim seu sentido público.

A construção de uma narrativa histórica capaz de fazer ver além da opacidade de um presente de horizontes políticos estreitos, de ações desencontradas e notícias falsas não é tarefa fácil, pois em momentos de crise social como a que vivemos atualmente, as guerras de narrativas em torno da verdade histórica se intensificam. Como diria Schwarcz (2019), condicionada pelas questões do presente, a história se transforma numa série de justificativas, enredo e canto de torcida organizada. Nessa disputa de narrativas, vemos entoar vozes dissonantes. No caso do racismo - objeto de análise deste texto - percebemos, de um lado, autoridades públicas, empresários e mesmo pessoas comuns negando a sua existência, e do lado oposto, outros atores sociais apresentando evidências que indicam o contrário. Posicionados do lado de cá, entendemos que contra o mito da democracia racial nada melhor do que os fatos e uma educação intercultural e crítica, capaz de criar condições para a compreensão dos processos históricos que estruturam as relações socioeconômicas expressas nas escalas local, nacional e global.

Este artigo - fruto de pesquisa bibliográfico-documental almeja contribuir para o debate público acerca do racismo no Brasil, bem como os desafios que ele representa para a 
Rede Federal de Educação Profissional, Científica e Tecnológica (RFEPCT), tendo como referência as Diretrizes Curriculares Nacionais para a Educação das relações étnico-raciais.

\section{MATERIAIS E MÉTODOS}

Trata-se de pesquisa de natureza básica, desenvolvida em abordagem qualitativa com suporte do método bibliográfico-documental, o qual articula fontes de informações de perfil bibliográfico, já tratadas e fontes documentais diversas, das quais muitas ainda não passaram por nenhum processo de tratamento.

O corpus documental constitui-se de livros, artigos científicos, relatórios, estatísticas e documentos oficiais, como: a Lei 10.639, de 09 de janeiro de 2003, que alterou a Lei 9.394, de 20 de dezembro de 1996, a qual estabelece as diretrizes e bases da educação nacional, para incluir no currículo oficial da Rede de Ensino a obrigatoriedade da temática "História e Cultura Afro-Brasileira", além de dar outras providências; a Lei 11.645, de 10 de março de 2008, que alterou a Lei 9.394, de 20 de dezembro de 1996, modificada pela Lei no 10.639, de 9 de janeiro de 2003, que estabelece as diretrizes e bases da educação nacional, para incluir no currículo oficial da rede de ensino a obrigatoriedade da temática "História e Cultura AfroBrasileira e Indígena"; o Decreto n. 4.886/2003, que instituiu a Política Nacional de Promoção da Igualdade Racial além de conferir outras providências; a Resolução n. 1, de 17 de junho de 2004, que instituiu as Diretrizes Curriculares Nacionais para a Educação das Relações Étnico-Raciais e para o Ensino de História e Cultura Afro-Brasileira e Africana.

$\mathrm{O}$ acesso às fontes acima elencadas foi realizado mediante pesquisa na internet no buscador Google e no Catálogo de Dissertações e Teses da USP, a partir do descritor "relações étnico-raciais", filtro temático "área de Educação" e filtro temporal "anos de 2017, 2018 e 2019".

Os documentos coletados foram fichados e serializados por tipo em editor eletrônico de texto e armazenados em nuvem do banco de dados deste estudo.

As análises foram desenvolvidas com base em literaturas representativas do pensamento social, dentre as quais Schwarcz (2019), Sampaio e Meneghetti (2020), Souza (2019), Almeida (2018), Silva e Silva Tobias (2016), Munanga (2015), dentre outros/as. 
As categorias de análise centrais a esta investigação são Racismo, Educação para as relações étnico-raciais e Educação Profissional e Tecnológica.

O conceito de racismo que norteia este estudo é o elaborado por Djamila Ribeiro, que o define como sistema de opressão que nega direitos (RIBEIRO, 2019). Este sistema é um produto moderno do colonialismo e da colonialidade, que continua a ser exercida a partir de quatro eixos principais: Colonialidade do Poder, Colonialidade do Saber, Colonialidade do Ser e Colonialidade da Mãe-Natureza (WALSH, 2007, 2010). Tais eixos atuam de forma a celebrar os sucessos intelectuais e epistêmicos europeus, ao passo que silenciam, deslegitimam e negam as outras epistemologias (WALSH, 2007).

A educação para as relações étnico-raciais é entendida como abordagem educativa que expressa uma ação afirmativa da diversidade cultural, racial, social e econômica brasileira. Ela deve compor o currículo de História, mas deve ser também transdisciplinar, de modo a promover reflexão crítica sobre as relações culturais territorialmente expressas e as estruturas socioeconômicas implicadas em suas dinâmicas. Essa abordagem educacional é vista como recurso necessário para o enfrentamento do racismo, a compreensão das diferenças e o enfrentamento das desigualdades.

A Educação Profissional e Tecnológica (EPT) por sua vez, é vista como modalidade educacional prevista na Lei de Diretrizes e Bases da Educação Nacional (LDB), cuja finalidade precípua é preparar para o trabalho, contribuindo para que o cidadão possa se inserir e atuar no mundo do trabalho e na vida em sociedade. O trabalho como princípio educativo é um motivador para promover a reflexão sobre o direito das pessoas de se reconhecerem como agentes de transformação, possibilitando construções intelectuais elevadas e apropriação de conceitos para a intervenção consciente na sua realidade. Para tanto, abrange cursos de qualificação, habilitação técnica e tecnológica, e de pós-graduação, organizados de forma a propiciar o aproveitamento contínuo e articulado dos estudos (MEC, 2019). A oferta dessa modalidade educacional na Rede Federal de Educação Profissional, Científica e Tecnológica tem o desafio de

[...] não se curvar às conveniências mercantilistas definidas pelo mercado de trabalho, nem tão pouco adequar-se à 'formação escolar', mas comprometerse com o refreamento das desigualdades sociais, a expansão socioeconômica, relacionadas à educação básica ofertada por uma escola pública de qualidade. Entretanto, esta modalidade de educação deve estar integrada ao 
mundo do trabalho, com diversas outras políticas e ações públicas e com a Lei de Diretrizes e Bases da Educação (NARCISO, 2015, p. 37).

É nesse sentido que se espera maior comprometimento de sua parte com a política nacional de educação para as relações étnico-raciais, mediante uma educação intercultural conseqüente, capaz de enfrentar tanto do ponto de vista epistêmico quando das práticas educacionais o colhimento da diversidade étnica e cultural de indígenas, quilombolas e outros povos e comunidades tradicionais existentes no Brasil.

\section{RESULTADOS E DISCUSSÃO}

\section{Miscigenação, escravidão "branda" e democracia racial - os mitos fundadores da república}

O estado republicano brasileiro formou-se com base em três mitos que se relacionam entre si: a miscigenação das três raças (branca, negra e indígena), a existência de uma escravidão "branda" e de uma postulada democracia racial. Tais mitos expressam o caráter violento e dissimulado de nossas relações sociais.

A miscigenação, exaltada por grandes nomes da cultura nacional, como Gilberto Freyre $(2000,2006)$ ocultam a cultura do estupro de mulheres negras e indígenas, que sentiram no corpo a violência do sistema escravista e das ideologias raciais expressas mediante teorias deterministas que grassaram no período imediatamente posterior à abolição. Hoje a questão da violência sexual praticada contra mulheres negras é amplamente debatida pelas feministas negras brasileiras, com destaque para Djamila Ribeiro, Sueli Carneiro e Conceição Evaristo - que denunciam a recalcitrância dessa prática inaceitável.

A escravidão "branda", na qual senhores e escravos teriam convivido de forma amistosa e mesmo afetiva, devido a relações de compadrio, de alcova ou mesmo por certa displicência dos primeiros, é absolutamente contrafactual, pois conforme ensina Lilia Schwarcz (2019), um sistema que se pauta na propriedade de uma pessoa sobre outra não tem nenhuma chance de ser benevolente. Ele pressupõe o uso intenso e extenso da mão de obra cativa, a vigilância constante, a falta de liberdade e o arbítrio. Assim, nunca foi fácil ser escravo no Brasil. 
A experiência da escravidão legou marcas indeléveis em nossa história, marcas essas que ainda persistem como desafio democrático. Não podemos esquecer que nesses nossos 520 anos de história, 388 foram de exploração do trabalho de africanos escravizados e de seus descendentes, os quais foram postos à margem da sociedade e espoliados de qualquer direito. Conforme Pacheco (2020, p. 4), "esta é a raiz de uma elite perversa, preconceituosa, antidemocrática e de uma sociedade marcada pelo preconceito e pela exclusão".

A democracia racial é outra fantasia exportada ao largo até meados da década de 1950, que fez até mesmo pessoas sagazes como Nelson Mandela se iludirem. Muitos acreditaram (e ainda acreditam) que no Brasil houve uma acomodação entre negros e brancos e que esses convivem pacificamente e desfrutam das mesmas oportunidades - o que não se sustenta quando se analisa as relações cotidianas, as notícias de jornais e as estatísticas mais básicas, como de mortalidade e expectativa de vida das pessoas negras no Brasil.

Esses discursos, amplamente difundidos, consolidaram uma falsa realidade, levando muitos a acreditarem que no Brasil não há racismo, mas apenas preconceito (um desvio do indivíduo), que as relações interétnicas são suaves e que há oportunidades iguais para todos. O estudo da História é relevante para desmontar essas crenças, problematizar as relações estabelecidas, promover a compreensão das diferenças e o convívio ético entre as pessoas.

\section{O racismo como estrutura}

No Brasil o racismo existe e é estrutural, é um dispositivo funcional para a reprodução da ordem vigente. Não se trata, portanto, de algo residual (resquício de nosso passado escravocrata, monarquista e pré-industrial), e nem mesmo de algo em retração, mas, ao inverso, de prática que se reproduz cotidianamente nas diversas esferas sociais e se afirma sem pudor, a contrapelo da lei, que define como imprescritíveis e inafiançáveis os crimes de tal ordem (BRASIL, 1988).

Seu caráter estrutural pode ser notado quando consideramos informações acerca do acesso das pessoas negras a emprego, ensino superior, rendimento econômico e cargos de liderança, ou quando detemos nosso olhar sobre dados do encarceramento, homicídio e feminicídio, mas há também um número infindável de palavras e gestos dispersos no cotidiano que materializam preconceitos e discriminações em função de cor, traços 
fenotípicos e origem étnica. Há expressões pejorativas perpetuadas mesmo na mais tenra idade como "cabelo de bombril" e outras ainda mais ofensivas, replicadas infinitamente por gerações que entram e saem das escolas dando uma continuidade perversa à discriminação e inferiorização de quem não apresente características físicas que se enquadram ao que a sociedade aponta como bonito/aceitável/padrão. Por opção teórico-metodológica nos concentraremos, neste texto, na análise do caráter estrutural do racismo manifesto no Brasil (seu caráter macro), sem nos determos aos aspectos individuais e institucionais do racismo que também são reais e relevantes.

Considerar o racismo como estrutural à sociedade brasileira significa dizer que ele está na base da reprodução das relações de desigualdade e violência, relações estas que ele normaliza mediante dispositivos variados de poder (ALMEIDA, 2018). Dentre esses dispositivos podem-se citar, dentre outros, discursos como o da meritocracia, que culpa os próprios negros, indígenas, quilombolas e outros povos e comunidade tradicionais pelas limitações socioeconômicas por eles enfrentadas, ocultando uma cadeia de privilégios e favorecimentos aos quais os brancos têm tido acesso desde o período colonial.

O racismo é produto da colonialidade e funciona como motor de desigualdades e instrumento de legitimação do biopoder. Para Foucault (1999) trata-se de dispositivo de poder que se impõe sobre o campo biológico como instrumento de definição do que deve viver e do que deve morrer: "E, claro, por tirar a vida não entendo simplesmente o assassínio direto, mas também tudo o que pode ser assassínio indireto: o fato de expor à morte, de multiplicar para alguns o risco de morte ou, pura e simplesmente, a morte política, a expulsão, a rejeição etc." (FOUCAULT, 1999, p. 306). Assim, quando se pensa no lugar social conferido aos afrodescendentes no Brasil, nas formas de tratamento a eles dispensadas, na criminalização de seus movimentos sociais, nas privações econômicas e na própria violência estatal a eles dirigida, seja por ação ou omissão, fica latente que se trata de um racismo estrutural que se expressa a partir de vários indicadores de desigualdade.

De acordo com Schwarcs (2019), a desigualdade social no Brasil é um dos mais graves problemas de nossa agenda republicana. Para ela,

Mão de obra escrava, divisão latifundiária da terra, corrupção e patrimonialismo, em grandes doses, explicam os motivos que fizeram do país uma realidade desigual. Não dão conta de esclarecer, porém, por que, a 
despeito do processo de modernização e de industrialização que o país conheceu no século XX, não conseguimos romper totalmente com esse círculo vicioso do passado.

O problema da desigualdade é crescente e talvez possa ser explicado pelo fato de que nunca tivemos uma política efetiva de redistribuição de renda, nunca promovemos de maneira radical a inclusão social dos mais pobres e porque o capitalismo funciona de modo a intensificar as dessimetrias sociais, a concentração de renda e poder, e não a reduzi-las.

O Boletim Especial do Departamento Intersindical de Estatística e Estudos Socioeconômicos (DIEESE) de 10/11/2020 informou que só no primeiro semestre de 2020, dos oito milhões de pessoas que perderam o emprego 6,3 milhões eram negros e negras, o equivalente a $71 \%$ do total. O mesmo documento informa que entre o $4^{\circ}$ trimestre de 2019 e o $2^{\circ}$ trimestre de 2020, 8,1 milhões de negros e negras estavam em situação vulnerável no país.

Mulheres e homens negros recebem menores salários e enfrentam maior dificuldade em conseguir emprego, por conseguinte, a taxa de desocupação entre eles é maior do que entre trabalhadores e trabalhadoras brancas. Preconceito racial e menor escolaridade são fatores que podem explicar esse fenômeno, que fere a dignidade da pessoa humana, prejudica suas condições de subsistência e reduz as possibilidades de mobilidade social. A pandemia de COVID-19 atua de modo a ampliar essas desigualdades e intensificar a vulnerabilidade dessa população.

Não obstante os desafios impostos pela pandemia em curso e a mortandade decorrente da virose emergente, Sampaio e Meneghetti (2020) chamam nossa atenção para outra "pandemia", que não é excepcional nem temporária, mas se revela cotidiana, sistemática, dirigida e focalizada. Seu alvo são negros, pobres e jovens. Segundo os autores, há uma política estatal de extermínio dessa população que se articula à criminalização (anterior ou posterior ao homicídio).

É sabido que a menor parte dos homicídios que ocorrem no Brasil é praticada por agentes do Estado investidos em cargos públicos, todavia, esse número é emblemático de uma política racial de extermínio de pessoas negras, que dado seu caráter reiterado e ordenado, não pode mais ser vista como mera coincidência ou ato isolado de profissionais despreparados. Ao compararmos a taxa de homicídios entre negros e não negros entre 2007 e 2017, foi possível constatar que, enquanto a taxa de homicídios de não negros aumentou 3,3\% no período, a taxa 
de homicídios de negros cresceu 33,1\% (IPEA, 2019). O homicídio de pessoas negras, de tão corriqueiro nos noticiários televisivos tende a ser encarado como algo natural e imutável e só quando o racismo é apontado como componente do crime é que essas notícias ganham maior proporção, mobilizando a opinião dos diversos segmentos populacionais.

Jovens negros (as) e pobres são mortos diariamente nas comunidades onde moram, dentro de suas próprias casas, nos pontos de ônibus e mesmo dentro de supermercados. A eles (as) é negada a presunção de inocência e a abordagem é quase sempre violenta. Pancadas, tiro à queima-roupa, bala perdida, asfixia, mas também abandono material, descaso, precariedade de serviços públicos, exposição a risco de morte são formas de extermínio sistematicamente aplicadas no Brasil. "Eu não consigo respirar" têm sido uma das frases mais repetidas por homens negros diante da violência policial, não só nos Estados Unidos, como também no Brasil, na França e em outras partes do mundo.

O Atlas da Violência de 2020 atesta que as principais vítimas de homicídio do país são a população negra e que as taxas de homicídio nesse segmento continuam crescentes:

[...] apenas em 2018, para citar o exemplo mais recente, os negros (soma de pretos e pardos, segundo classificação do IBGE) representaram $75,7 \%$ das vítimas de homicídios, com uma taxa de homicídios por 100 mil habitantes de 37,8. Comparativamente, entre os não negros (soma de brancos, amarelos e indígenas) a taxa foi de 13,9 , o que significa que, para cada indivíduo não negro morto em 2018, 2,7 negros foram mortos. Da mesma forma, as mulheres negras representaram $68 \%$ do total das mulheres assassinadas no Brasil, com uma taxa de mortalidade por 100 mil habitantes de 5,2, quase o dobro quando comparada à das mulheres não negras (IPEA, 2020, p. 47).

A combinação de racismo e marginalização social é a fórmula nefanda que tem resultado no extermínio das populações negras pela violência do próprio Estado, em particular a violência policial (IPEA, 2019). Para Sampaio e Meneghetti (2020) a criminalização que ocorre por dentro da lei e o extermínio praticado fora da lei não são polos opostos, mas se conectam em várias medidas. A esse respeito, Meneghtti esclarece que:

A criminalização não é uma alternativa legal e humanizada ao genocídio, pois, na verdade, é ela quem permite ou viabiliza a matança de jovens pobres e negros. Em todo caso, a criminalização antecede ou sucede ao genocídio, podendo se dar até postumamente, como forma de justificativa. É por isso que, quase sempre, a vítima tinha "passagem" ou era considerada "suspeita", reagindo ou não à ação das forças de segurança. Nessa parte periférica do mundo, o genocídio criminaliza e a criminalização mata, tudo ao mesmo 
tempo, sendo mais correto falar do par genocídio-criminalização (MENEGHETTI, 2018, p. 6).

O encarceramento da população negra (em grande medida sem o cumprimento do devido processo legal) é outro dado relevante que aponta para a existência de racismo estrutural. O Brasil tem a terceira maior população carcerária do mundo e dessa população a maior parte é negra (SINHORETTO, 2015).

De acordo com o Levantamento nacional de informações penitenciárias (BRASIL, 2019), a maior parte da população carcerária é composta por jovens, sendo $54 \%$ com idade entre 18 e 29 anos. Em relação à raça/etnia, enquanto 35,4\% são brancos, o total de negros (incluindo pretos e pardos) chega a 66,3\%. Em análise sobre os dois elementos (homicídio e encarceramento), Cintra (2019, p. 240) destaca que, “[...] tanto a morte do corpo negro como sua não liberdade, resultantes da lógica de acumulação e da gramática do sofrimento e do terror, não são somente previstas, mas esperadas e organizadas por diversos atores sociais dentro da lógica da supremacia branca, balizadora da lógica do capital.”

O tratamento diferenciado conferido a negros e não negros, as variações nas abordagens, as condições diferenciadas de acesso a recursos são indicativas da persistência de crenças na existência de superioridade racial branca. Não se trata, contudo, de um problema meramente cultural, mas político, de uma estratégia para a manutenção da ordem de privilégios historicamente constituída sobre a exploração e subjugação das populações africanas e de seus descentes.

O racismo não se limita, contudo, às relações humanas, mas perpassa as diversas esferas sociais e cristaliza-se nos diversos objetos culturais, estando presente, desse modo, também nos espaços formais de educação, nos livros didáticos e nos currículos eurocêntricos que reproduzem a violência epistêmica contra os saberes não hegemônicos - o que contribui para transformar diferenças étnicas e raciais em desigualdades, conforme indica Marchesi (2009).

Na gênese desse problema está o colonialismo que processou ora a eliminação física do 'outro', ora sua escravização, resultando em uma violenta forma de negação de sua alteridade. Nesse contexto, a educação escolar no continente americano exerceu um papel 
fundamental no processo de homogeneização cultural, que teve como função a consolidação de uma cultura de base ocidental e eurocêntrica (CANDAU; RUSSO, 2010). Outrossim, a superação do racismo passa pela necessidade de recuperação/recomposição das epistemologias silenciadas e pelo desenvolvimento de uma educação intercultural capaz de redimensionar as relações e padrões éticos.

\section{OS DESAFIOS DA EPT FRENTE AO RACISMO}

Uma vez que o racismo é estrutural às relações socialmente estabelecidas no Brasil, manifesta-se mediante expressões variadas e se faz presente no sistema nacional de ensino, na Rede Federal de Educação Profissional, Científica e Tecnológica (RFEPT) e nos Institutos, apesar de sua filosofia progressista e comprometida com a emancipação da classe trabalhadora e com a promoção de relações mais justas.

Para o enfrentamento do racismo, o Estado brasileiro tem envidado esforços como os representados pela Lei 10.639, de 09 de janeiro de 2003, que alterou a Lei $n^{\circ}$ 9.394, de 20 de dezembro de 1996, para incluir no currículo oficial da Rede de Ensino a obrigatoriedade da temática "História e Cultura Afro-Brasileira", além de dar outras providências; pelas Diretrizes Curriculares Nacionais para a Educação das Relações Étnico-Raciais e para o Ensino de História e Cultura Afro-Brasileira e Africana, estabelecida por meio da Resolução $\mathrm{n}^{\circ}$ 1, de 17 de junho de 2004 do Conselho Nacional de Educação; pelo Decreto n. 4.886/2003, que instituiu a Política Nacional de Promoção da Igualdade Racial além de outras providências, assim como pela Lei 11.645 , de 10 de março de 2008, que alterou a Lei no 9.394, de 20 de dezembro de 1996, modificada pela Lei no 10.639 , de 9 de janeiro de 2003, que estabelece as diretrizes e bases da educação nacional, para incluir no currículo oficial da rede de ensino a obrigatoriedade da temática "História e Cultura Afro-Brasileira e Indígena". Mesmo diante do estabelecido nas leis ainda podemos verificar em alguns livros didáticos a ausência do tema e em muitos o tratamento superficial limitando-se a uma seção sobre o tema, ao invés de tratar de forma contextualizada e transversal dentro de todo o material elaborado, visto que a história e cultura Afro-Brasileira é parte integrante da nossa história e não um capítulo à parte. 
Neste tópico teceremos considerações acerca do perfil das Diretrizes Curriculares Nacionais para a Educação das Relações Étnico-Raciais e para o Ensino de História e Cultura Afro-Brasileira e Africana e da atuação da RFEPCT em relação a ela, ponderando seus elos de fragilidade e de força no combate ao racismo.

Antes de qualquer coisa, enfatizamos que assumir o compromisso com a educação para as relações étnico-raciais é necessário para a ampliação da cidadania, a redução das desigualdades sociais e da discriminação. Nesse sentido, as Diretrizes em questão posicionam-se como ação positiva, de perfil diretivo e compensatório, que tem por foco reduzir a desigualdade que se expressa em duas vertentes: a primeira é a da exclusão de negros do sistema educacional, materializada nas dificuldades de acesso e permanência que se conjugam em baixa escolaridade, e a segunda é a do próprio preconceito presente nos espaços escolares, nas práticas que aquele espaço comporta e, de maneira mais sutil, nos próprios currículos.

Em relação ao primeiro aspecto, o texto introdutório às Diretrizes Curriculares Nacionais para a Educação das Relações Étnico-Raciais e para o Ensino de História e Cultura Afro-Brasileira e Africana, publicada em 2004, rememora que o Brasil, nos diversos períodos de sua história política manteve uma postura ativa e permissiva diante da discriminação e do racismo, exemplificando dispositivos jurídicos que contribuíram para isso. Dentre esses dispositivos, destaca-se o Decreto $\mathrm{n}^{\mathrm{o}} 1.331$, de 17 de fevereiro de 1854, que estabelecia que nas escolas públicas do país não seriam admitidos escravos, e que a previsão de instrução para adultos negros dependeria da disponibilidade de professores. O Decreto $\mathrm{n}^{\mathrm{o}}$ 7.031-A, de 6 de setembro de 1878, por seu turno, estabelecia que os negros só poderiam estudar no período noturno.

Hodiernamente, com a vigência da Constituição de 1988, o estado brasileiro busca consolidar-se como Estado Democrático de Direito, afirmando a dignidade da pessoa humana, o valor da cidadania e a condenação ao racismo. As práticas escolares, contudo, ainda são desafiadas pelo racismo, seja pelo que se expressa no currículo, preponderantemente eurocêntrico, seja nas interações sociais, no preconceito lingüístico, nas dificuldades econômicas que desfiam a permanência e o êxito escolar das populações afrodescendentes e indígenas. 
Encontramo-nos diante, portanto, de inúmeros desafios que precisam ser trabalhados para construirmos relações interculturais mais justas e éticas. Esses desafios foram nomeados por Candau (2005): adentrar no universo de preconceitos e discriminações presentes na sociedade brasileira; questionar o caráter monocultural e o etnocentrismo; articular igualdade e diferença; problematizar os processos de construção das nossas identidades culturais; promover experiências de interação sistemática com os 'outros'; reconstruir a dinâmica educacional; favorecer processos de empoderamento.

As Diretrizes Curriculares Nacionais para a Educação das Relações Étnico-Raciais e para o Ensino de História e Cultura Afro-Brasileira e Africana apontam caminhos possíveis para a superação desses desafios, contudo, parece prevalecer no documento um tom culturalista, que sugere maior preocupação com os aspectos comportamentais do indivíduo do que com a dimensão política e econômica do problema. No texto de Apresentação do documento, assinado por Matilde Ribeiro, então Ministra Chefe da Secretaria Especial de Políticas de Promoção da Igualdade Racial (SEPPIR) é possível ler que uma das preocupações dessa política é "estimular a formação de valores, hábitos e comportamentos que respeitem as diferenças e as características próprias de grupos e minorias" (BRASIL, 2004, p. 7). Não há dúvidas de que estimular valores, hábitos e comportamentos éticos em relação à diversidade é atribuição compatível com o papel da educação, contudo é fundamental uma abordagem mais aprofundada, que afirme a diferença em seus aspectos históricos, políticos, sociais e de poder (SANTIAGO, AKKARI, MARQUES, 2013).

Os objetivos das referidas Diretrizes e as expectativas em relação ao ensino de História e Cultura Afro-Brasileira e Africana estão expressos nos dois primeiros parágrafos do Artigo $2^{\circ}$ :

Art. $2^{\circ}$ As Diretrizes Curriculares Nacionais para a Educação das Relações Étnico-Raciais e para o Ensino de História e Cultura Afro-Brasileira e Africana constituem-se de orientações, princípios e fundamentos para o planejamento, execução e avaliação da Educação, e têm por meta, promover a educação de cidadãos atuantes e conscientes no seio da sociedade multicultural e pluriétnica do Brasil, buscando relações étnico-sociais positivas, rumo à construção de nação democrática.

$\S 1^{\circ}$ A Educação das Relações Étnico-Raciais tem por objetivo a divulgação e produção de conhecimentos, bem como de atitudes, posturas e valores que eduquem cidadãos quanto à pluralidade étnico-racial, tornando-os capazes de interagir e de negociar objetivos comuns que garantam, a todos, respeito aos 
direitos legais e valorização de identidade, na busca da consolidação da democracia brasileira.

$\S 2^{\circ} \mathrm{O}$ Ensino de História e Cultura Afro-Brasileira e Africana tem por objetivo o reconhecimento e valorização da identidade, história e cultura dos afro-brasileiros, bem como a garantia de reconhecimento e igualdade de valorização das raízes africanas da nação brasileira, ao lado das indígenas, européias, asiáticas.

As Diretrizes em questão são orientações para o bom cumprimento da Lei 10.639, de 09 de janeiro de 2003. Somam-se à Política Nacional de Promoção da Igualdade Racial, criada pelo Decreto n. 4.886/2003 e inserem-se na esteira das Políticas de Reparações, de Reconhecimento e Valorização de Ações Afirmativas. Vale destacar ainda que, além da Lei 10.639, de 09 de janeiro de 2003, uma nova Lei: a 11.645, de 10 de março de 2008 veio se somar à primeira, reforçando o objeto já definido na primeira e acrescentando a temática indígena, que já aparecia na Lei 10.639, de 09 de janeiro de 2003, mas de forma tangencial e sem a ênfase esperada pelo movimento indígena.

Para Munanga (2015), os documentos citados contribuem para uma correção do esquecimento e da memória positiva da escravidão na história do Brasil. Elas podem ser lidas também na esteira das produções decoloniais, que desnudam "a desumanização e as lutas dos povos historicamente subalternizados para, então, construir outros modos de viver, de poder e de saber (PAIM, ARAÚJO, 2018, p. 6).

Cabe ressaltar ainda que, o estudo da história e da cultura africana e afro-brasileira e indígena é recurso eficaz para a compreensão dos processos formadores do Brasil e da problemática de sua identidade nacional, constituindo-se em instrumento para as lutas do presente, pois, "ao nos olharmos como resultados de processos que uniram diferentes povos, percebemos que quanto melhor conhecermos os sistemas culturais daqueles que nos formaram, melhor conheceremos nossos antepassados imediatos, nós mesmos e nosso presente (SOUZA, 2004, p. 43).

Ainda no que concerne à inclusão do componente "História e Cultura Afro-Brasileira" (assim como da história e cultura indígena) nos currículos de História do Brasil, Artes, Língua Portuguesa e suas Literaturas é pertinente ressaltar que não se trata de mera mudança de foco (de um currículo eurocêntrico para um afrocêntrico ou ameríndio), mas da inclusão de novos tópicos concernentes à diversidade cultural, racial, social e econômica brasileira que 
transcendam o caráter de mera "curiosidade" ou "folclore", mas mobilizem reflexões que repensem de forma ampla as relações étnico-raciais. E não só isso. Que favoreçam também a reflexão sobre as próprias práticas pedagógicas, seus sentidos e intencionalidades no conjunto mais amplo das relações culturais estabelecidas.

O Parecer do Conselho Nacional de Educação (CNE, 2004) a respeito das Diretrizes Curriculares Nacionais para a Educação das Relações Étnico-Raciais e para o Ensino de História e Cultura Afro-Brasileira e Africana deixa claro se tratar de um dever do Estado, a quem cabe promover e incentivar políticas de reparações a fim de cumprir ao disposto no Artigo 205 da Constituição Federal, que define o dever de garantir indistintamente, por meio da educação, direitos e oportunidades iguais para o pleno desenvolvimento de todos e todas. O Parecer referido entende que sem a intervenção do Estado, as pessoas marginalizadas, dentre as quais as afrobrasileiras, dificilmente romperão o sistema meritocrático que intensifica as desigualdades e amplia as injustiças.

Desta forma, vemos que o estado como responsável por exercer a vontade coletiva, por meio de um governo eleito e de instituições representativas, deve assegurar os direitos dos cidadãos através de políticas públicas universais e específicas. Cabe aos órgãos fiscalizadores e a população que geralmente não faz uso de sua força de persuasão controlar os representantes políticos que elaboram e executam as políticas públicas.

O caráter compensatório também transparece no Parecer do CNE em análise, quando registra que:

A demanda por reparações visa a que o Estado e a sociedade tomem medidas para ressarcir os descendentes de africanos negros, dos danos psicológicos, materiais, sociais, políticos e educacionais sofridos sob o regime escravista, bem como em virtude das políticas explícitas ou tácitas de branqueamento da população, de manutenção de privilégios exclusivos para grupos com poder de governar e de influir na formulação de políticas, no pós-abolição. Visa também a que tais medidas se concretizem em iniciativas de combate ao racismo e a toda sorte de discriminações (CNE, 2004, p. 11).

A produção de documentos que confirmem a existência do racismo e afirme a intenção de superá-lo é importante para o enfrentamento do negacionismo e a superação do mito da democracia racial. A questão permanece, contudo, desafiadora. Reconhecemos que muitas vezes o racismo é praticado de maneira inconsciente, e em outras tantas é mantido por 
dificuldades em transcender barreiras burocráticas, sem prejuízo dos demais fatores incidentes, como a insuficiência de uma política de formação docente para a educação acerca das relações étnico-raciais e falta de recursos materiais para investir em projetos do gênero.

Esses desafios se fazem notar na RFEPCT. Resta mapeá-los. Sem termos tido a pretensão de cartografar esse problema na Rede federal de EPT, enunciaremos alguns pontos de fragilidade que nos chamaram a atenção:

1- Não há uma política conseqüente de educação para as relações étnico-raciais, estando essa limitada aos espaços das disciplinas de História, Artes, Língua Portuguesa e Literatura;

2- Não há um programa de fomento para pesquisas e publicações na área;

3- Não há ações continuadas de formação em serviço para o trato do tema no espaço escolar;

4- Baixos investimentos de recursos nos núcleos que abordam a questão: NEABI, NEDET, NAPNE;

5- Falta de integração em rede das ações desenvolvidas;

6- Não há uma metodologia de acompanhamento e de apoio para o cumprimento das diretrizes nacionais para a educação das relações étnico-culturais e para o ensino de História e Cultura Afro-Brasileira, Africana e Indígena, assim como em relação às leis 10.639/2003 e 11.645/08, o que faz como a discricionariedade se sobreponha às políticas afirmativas.

Tais gargalos poderiam ser superados com investimentos e trabalho colaborativo em rede, sem ônus elevado para o Estado e com possibilidade de resultados positivos relevantes para a sociedade, a começar pela melhoria das relações interétnicas entre os próprios estudantes.

Esses investimentos não resolveriam o problema do racismo no Brasil, mas indicariam um compromisso com a mudança da ordem estabelecida, uma ação que se opõem à passividade e ao conformismo.

Embora não esteja isenta de contradições a RFEPCT em geral, e os Institutos Federais de Educação Ciência e Tecnologia (IF), em particular, demonstram elevado potencial em promover uma educação intercultural crítica, empenhada na inclusão educacional de 
afrodescendentes, de indígenas, de quilombolas, de pomeranos, caiçaras e demais povos e comunidades tradicionais que configuram a diversidade étnica e cultural brasileira. Ao promover um balanço do trabalho da RFEPCT, Frigotto destaca que os pontos positivos se sobrepõem aos negativos:

Cabe ressaltar, todavia, que o balanço de pontos positivos da expansão, com a inclusão de milhares de jovens nessas instituições, pela geração de centenas de empregos qualificados e pela mudança que a interiorização impacta em todos os níveis, econômico, cultural e político, nas pequenas e médias cidades, é muito maior que os problemas. Ressaltamos a inclusão de quilombolas, índios e alunos provenientes de extratos populares que jamais teriam ingressado num ensino médio de qualidade e possibilidade de ensino superior sem a criação, expansão e interiorização dos IFs (FRIGOTTO, 2018, p. 148).

Essas ações têm sido possíveis porque, conforme Pacheco (2020), os IF representam não apenas uma admirável expansão da Educação Profissional e Tecnológica, mas o estabelecimento de novos paradigmas fundados na Politecnia.

Segundo o autor (op. cit.), trata-se de uma institucionalidade inédita na estrutura educacional brasileira, notadamente marcada por uma dualidade (que apresenta também cunho racista), na medida em que segregou das escolas de formação geral e de formação superior (universidades) as pessoas de condição econômica desfavorável, reservando esses espaços para os filhos das elites, que exerceriam os cargos de liderança política e econômica. Aos filhos das classes trabalhadores, frequentemente negros e pobres, a única opção ofertada era a de uma educação tecnicista e instrumental, preparadora para o exercício de ofícios, porém incapaz de instigar a reflexão sobre a estrutura racializada de poder vigente em nossa sociedade.

Ao historicizar a EPT no Brasil, Moura (2007) ressalta que a origem dessa modalidade educacional relaciona-se a uma perspectiva assistencialista, e informa que,

Ainda no século XIX, foram criadas sociedades civis destinadas a dar amparo a crianças órfãs e abandonadas, possibilitando-lhes uma base de instrução teórica e prática e iniciando-as no ensino industrial. Entre estas sociedades, as mais importantes foram os Liceus de Artes e Ofícios do Rio de Janeiro (1858), de Salvador (1872), do Recife (1880), de São Paulo (1882), de Maceió (1884) e de Ouro Preto (1886). Essa lógica assistencialista com que surge a educação profissional é perfeitamente coerente com uma sociedade escravocrata originada de forma dependente da 
coroa portuguesa, que passou pelo domínio holandês e recebeu a influência de povos franceses, italianos, poloneses, africanos e indígenas, resultando em uma ampla diversidade cultural e de condições de vida ao longo da história - uma marca concreta nas condições sociais dos descendentes de cada um destes segmentos (MOURA, 2007, p. 6).

Diante do exposto, a criação dos IF expressa uma mentalidade moderna pautada na política de inclusão com desenvolvimento, que só é possível com o empoderamento social - o que demanda ir além do assistencialismo. Desse modo, trata-se de política pública comprometida com a formação para o trabalho e a formação para o exercício da cidadania, sem dissociá-las. Preconiza a atuação junto a territórios e populações com maior vulnerabilidade social objetivando integrá-las à cidadania e aos processos de desenvolvimento com inclusão (PACHECO, 2020).

Ainda conforme o autor,

[...] não se trata de ignorar a dimensão do trabalho enquanto prática econômica destinada à sobrevivência do homem e à produção de riquezas, mas de entendê-lo em sua dimensão ontológica e como prática social. [...] quanto maior a compreensão desta dinâmica econômica e social, melhores condições de interferir neste processo histórico o trabalhador terá. O homem é um ser histórico, agindo dentro de determinadas circunstâncias e condicionado em sua ação por estas e pela cultura da época. Um dos papéis da educação é além de possibilitar o acesso aos conhecimentos específicos, promover a reflexão crítica sobre os padrões culturais vigentes e as formas de desenvolvimento progressista das forças produtivas, possibilitando o estabelecimento de relações sociais cada vez mais justas e igualitárias (PACHECO, 2020, p. 11).

Nesse sentido, a RFEPCT, por meio dos IF, ao considerar as múltiplas dimensões do trabalho e almejar promover reflexão crítica sobre os padrões culturais vigentes demonstra compromisso com uma educação libertadora, empenhada no enfrentamento da desigualdade que perpassa todo o tecido social. Sua proposta político-pedagógica vai, portanto, ao encontro de uma educação intercultural crítica, a qual é indispensável para ampliar a inclusão e redimensionar as relações interétnicas no Brasil.

Quanto a nós, educadores, conscientes de nosso papel na sociedade, cabe exercer a função docente conforme coloca Paulo Freire (2002, p.28) “O educador democrático não pode negar-se o dever de, na sua prática docente, reforçar a capacidade crítica do educando, sua 
curiosidade, sua insubmissão". Quando todos chegarmos à consciência do poder da insubmissão, alcançaremos a libertação.

\section{CONSIDERAÇÕES FINAIS}

O racismo é estrutural e representa um dos desafios mais urgentes do estado brasileiro. Ele resulta de nossa experiência colonial, que articulou colonialismo e colonialidade, autoritarismo e violência, mas é também produzido e reproduzido no presente. A ele se agregam novas crenças, representações e interpretações dos fenômenos sociais, revitalizando equívocos, preconceitos, ódios, privilégios e opressões.

Seus efeitos sociais são perversos: desigualdade socioeconômica e de oportunidades, subtração de direitos, interdição de liberdades, humilhação social, ampliação de riscos e vulnerabilidades, em suma, violência física e simbólica capaz de culminar na morte física e na morte política.

Políticas públicas e ações legais, seja em escala nacional, seja na escala das instituições são necessárias, mas não são suficientes para por fim ao racismo. De igual modo, uma educação para as relações étnico-raciais é primordial, mas por si só insuficiente. Por se tratar de um problema multidimensional o combate ao racismo requer profundas transformações econômicas, sociais, políticas e culturais.

Embora exista uma dimensão pessoal e ética em torno do enfrentamento do racismo espera-se que cada pessoa haja de modo a respeitar as diferenças, mesmo aquelas com as quais não concorda, também é salutar indicar o benefício de ações coletivas, sejam no âmbito dos movimentos sociais, das igrejas, das instituições públicas e do terceiro setor. Como se trata de um desafio grande, os esforços colaborativos e em rede tendem a ser mais eficientes no que se refere à manutenção do ânimo de transformação social.

A Rede Federal de Educação Profissional, Científica e Tecnológica tem elevado potencial em contribuir para a contraposição ao racismo, sobretudo por meio dos Institutos Federais de Educação, Ciência e Tecnologia, tendo em vista seus objetivos e princípios político-pedagógicos. Recomenda-se à Rede maior atenção ao cumprimento das Diretrizes Nacionais para a educação das relações étnico-raciais e ao cumprimento das Leis 10.639/2003 
e 11.645/2008 - o que pode ser feito mediante criação de um programa de fomento para pesquisa, publicação e desenvolvimento de projetos educativos acerca da temática, estabelecimento de metas e desenvolvimento de metodologia de acompanhamento e avaliação de resultados.

\section{REFERÊNCIAS}

ALMEIDA, Silvio Luiz de. O que é racismo estrutural? Belo Horizonte (MG): Letramento, 2018.

BASTIDE, Roger; FERNANDES, Florestan. Brancos e negros em São Paulo: ensaio sociológico sobre aspectos da formação, manifestações atuais e efeitos do preconceito de cor na sociedade brasileira. São Paulo: Global, 2008.

BRASIL. República Federativa. Lei 10.639, de 9 de janeiro de 2003. Brasília: Congresso Nacional, 2003.

BRASIL. República Federativa. Decreto n. 4.886, de 10 de novembro de 2003. Brasília: 2003b.

BRASIL. República Federativa. Lei no 9.394, de 20 de dezembro de 1996. Brasília: 1996.

BRASIL. República Federativa do. Lei 11.645, de 10 de março de 2008.

CANDAU, Vera Maria Ferrão; RUSSO, Kelly. Interculturalidade e Educação na América Latina: uma construção plural, original e complexa. Rev. Diálogo Educ., Curitiba, v. 10, n. 29, p. 151-169, jan./abr. 2010.

CANDAU, Vera Maria. Sociedade Multicultural e Educação: tensões e desafios. In: CANDAU, Vera Maria (org). Cultura (as) e Educação: entre o crítico e o pós-crítico. Rio de Janeiro: DP\&A, 2005.

CNE. Conselho Nacional de Educação. Resolução n 1, de 17 de junho de 2004.

CNE. Conselho Nacional de Educação Parecer às Diretrizes Curriculares Nacionais para a Educação das Relações Étnico-Raciais e para o Ensino de História e Cultura AfroBrasileira e Africana.

DIEESE. Departamento Intersindical de Estatística e Estudos socioeconômicos. Boletim Especial Desigualdade entre negros e brancos se aprofunda durante a pandemia. Disponível em: https://www.dieese.org.br/boletimespecial/2020/boletimEspecial03.pdf Acesso em 20 nov. 2020. 
FREIRE, Paulo. Pedagogia da Autonomia: Saberes Necessários à Prática Educativa. São Paulo: Paz e Terra, 2002.

FREYRE, Gilberto. Casa grande e senzala: formação da família brasileira sob o regime da economia patriarcal. São Paulo: Global, 2006.

FREYRE, Gilberto. Sobrados e mucambos: decadência do patriarcado rural e desenvolvimento do urbano. Rio de Janeiro/São Paulo: Record, 2000.

FRIGOTTO. Gaudêncio. Indeterminação de identidade e reflexos nas políticas institucionais formativas dos IFs. In: FRIGOTTO, Gaudêncio. (org.). Institutos Federais de Educação, Ciência e Tecnologia: relação com o ensino médio integrado e o projeto societário de desenvolvimento. Rio de Janeiro: UERJ, LPP, 2018. p. 125-150.

FOUCAULT, Michel. Em defesa da sociedade: curso no Collège de France (1975-1976). São Paulo: Martins Fontes, 1999.

IPEA. Instituto de Pesquisas Econômicas Aplicadas. Atlas da Violência 2020. Disponível em: https://www.ipea.gov.br/atlasviolencia/download/24/atlas-da-violencia-2020 Acesso em 20 nov. 2020.

MARCHESI, Ivani de Lurdes. Procedimentos didáticos para combater o Racismo, o Preconceito e Discriminação. Franca: Cristal, 2009

MEC. Ministério da Educação. Educação Profissional e Tecnológica (EPT). Disponível em: http://portal.mec.gov.br/educacao-profissional-e-tecnologica-ept Acesso em 01 jul. 2019.

MENEGHETTI, Gustavo. Na mira do sistema penal: o processo de criminalização de adolescentes pobres, negros e moradores da periferia. Rio de Janeiro: Lumen Juris, 2018.

MOURA, Dante. Educação básica e educação profissional e tecnológica: dualidade histórica e perspectivas de integração. Holos, Ano 23, Vol. 2 - 2007, pp. 1-27.

MUNANGA, Kabengele. Por que ensinar a história da África e do negro no Brasil de hoje? Revista do Instituto de Estudos Brasileiros, Brasil, n. 62, p. 20-31, dez. 2015.

NARCISO, Luciana Gusmão. S. Análise da evasão nos cursos técnicos do Instituto Federal do Norte de Minas Gerais - Câmpus Arinos: exclusão da escola ou exclusão na escola? Dissertação de Mestrado, 262f. Universidade Federal de Santa Catarina: Programa de Pós Graduação em Sociologia Política (PPGSP), Florianópolis, 2015.

PACHECO, Eliezer. Desvendando os institutos federais: identidade e objetivos. Educação Profissional e Tecnológica em Revista, v. 4, $\mathrm{n}^{\circ}$ 1, 2020

pp. 1-19. 
PAIM, Elison Antonio; ARAÚJO, Helena Maria Marques. Memórias outras, patrimônios outros, e decolonialidades: contribuições teórico-metodológicas para o estudo de história da África e dos afrodescendentes e de história dos Indígenas no Brasil. Archivos Analíticos de Políticas Educativas/Education Policy Analysis Archives, vol. 16, n. 1, 2018.

RIBEIRO, Djamila. Pequeno Manual Antirracista. São Paulo: Companhia das Letras, 2019.

SAMPAIO, Simone Sobral; MENEGHETT, Gustavo. Entre a vida e a morte: Estado, racismo e a "pandemia do extermínio" no Brasil. R. Katál., Florianópolis, v. 23, n. 3, p. 635-647, set./dez. 2020.

SANTIAGO, Mylene Cristina; AKKARI, Abdeljalil; MARQUES, Luciana Pacheco. Educação Intercultural: desafios e possibilidades. Petrópolis: Vozes, 2013.

SCWARCZ, Lilia. Sobre o autoritarismo brasileiro. São Paulo Companhia das Letras, 2019.

SILVA, Roberto da; SILVA TOBIAS, Juliano da. A educação para as relações étnico-raciais e os estudos sobre racismo no Brasil. Revista do Instituto de Estudos Brasileiros, núm. 65, diciembre, 2016, pp. 177-199.

SINHORETTO, Jacqueline. Mapa do encarceramento: os jovens do Brasil. Brasília: Presidência da República, 2015.

SOUZA, Marina de Mello. Em busca das conexões. In: ROCHA, M. J.; PANTOJA, S. (orgs). Rompendo Silêncios: historia da África nos currículos escolares. Brasília: DP Comunicações, 2004.

WALSH, Catherine. Interculturalidad y Colonialidad del Poder: Un pensamiento y posicionamiento "otro" desde la diferencia colonial. In: CASTRO-GÓMEZ, Santiago.; GROSFOGUEL, Ramón. (Org.). El Giro Decolonial: Reflexiones para una diversidad epistémica más allá del capitalismo global.Bogotá: Siglo del Hombre Editores; Universidad Central, Instituto de Estudios Sociales Contemporáneos y Pontificia Universidad Javeriana, Instituto Pensar, 2007, pp. 47-62.

WALSH, Catherine. Interculturalidad crítica y educación intercultural. In: UZIEDA, Jorge Viaña; MEALLA, LUIS Tapia.; WALSH, Catherine. Construyendo Interculturalidad Crítica. 3. ed. La Paz, Bolivia: CAB Instituto Internacional de Integración del Convenio Andrés Bello, 2010, pp. 75-97. 